\title{
Developing a public health pipeline: key components of a public health leadership program
}

\author{
Alina L Flores ${ }^{1 *}$, Kristina Risley ${ }^{2}$ and Kenneth Quintana ${ }^{3}$ \\ ${ }^{1}$ Centers for Disease Control and Prevention, National Center on Birth Defects and Developmental Disabilities, Prevention Research and Translation Branch, USA \\ ${ }^{2}$ University of Illinois at Chicago, School of Public Health, Doctor of Public Health in Leadership, USA \\ ${ }^{3}$ Centers for Disease Control and Prevention, Human Resources Office, Strategic Programs Office, USA
}

\begin{abstract}
Thirty percent of federal public health employees were retirement eligible in September 2017. Further, at the state public health level, as indicated in the recent Public Health Workforce Interests and Needs Survey, an estimated 25\% of employees are planning to retire before 2020 with an additional 18\% intending to leave their organizations within one year. Due to these workforce changes, there is an urgent need for public health organizations to examine how they are ensuring a talent pool from which leaders can emerge. As a large federal public health agency, the Centers for Disease Control and Prevention faces the challenge of providing leadership development to staff. Factors were examined that agency leaders identified as key components of a leadership development program to transition scientific public health staff into supervisory leadership roles. While many factors contribute to leadership development, participants more often identified training, provision of opportunities, mentors, and identification of high potential employees as key components of a leadership development program. With the need to develop organizational leaders to be ready when vacancies become available, findings from this study can inform the development and implementation of public health leadership development programs.
\end{abstract}

\section{Introduction}

A divide between evolving public health needs and the capacity of the workforce requires strong leadership skills and effective avenues for recruiting and retaining talent [1]. The urgency of such efforts are heightened given that many organizations are losing employees opting for retirement $[2,3]$. In the federal public health system, $30 \%$ of employees were retirement eligible in September 2017 [4]. At the state public health level, as indicated in the recent Public Health Workforce Interests and Needs Survey (PH WINS), an estimated 25\% of employees are planning to retire before 2020, with an additional $18 \%$ intending to leave their organizations within one year [5]. With more than a quarter of these employees being administrators and managers, many of these vacancies are in leadership roles.

Calls for public health infrastructure improvements in the literature [6-9] encourage public health organizations to take a deeper look at how they are ensuring a viable talent pool from which leaders can emerge. According to the Government Accountability Office, a growing retirement eligible pool requires that organizations assess key skills and competencies necessary to meet programmatic objectives and develop ways to recruit and retain talent to address vacancies [10]. A recent Public Health 3.0 report echoed the need for creative ways to recruit and retain a talented workforce, including staff with skills and experience beyond those generally attributed to public health [11]. A lack of leadership development programs among public health organizations [12] and a mismatch between leadership development offerings and skills needed for leadership in today's public health workforce [13] point to an underdeveloped talent pool. For example, a recent report by the de Beaumont Foundation [14] highlighted the gap between the discipline-specific skills of the current governmental public health workforce and the "vision and leadership" required to address complicated health demands. The report puts forth five recommendations for enhancing workforce capacity; one of which is to develop effective and engaging training. While, at its core, this recommendation aims to address the identified divide, implementation would need to account for an organization's unique situation.

Of notable concern are public health organizations that employ highly scientific experts. These organizations need specific guidance to help them transition such experts into supervisory roles requiring broader leadership skills. Many scientific experts lack adequate training, exposure to what supervisory roles entail, and opportunities to branch out beyond their specific disciplines, resulting in leadership skill deficits [15]. Competing priorities and a lack of targeted guidance on what such development should or could look like, have pushed such training and development to the back burner - putting public health organizations at risk for losing effectiveness and relevance.

The health demands of the public are rapidly changing [16]. With change comes the need for a workforce trained to meet and adapt to these demands $[17,18]$. Without a consistent, proactive approach to filling leadership vacancies with employees who have the necessary skills and competencies, public health organizations risk leaving their personnel and programs vulnerable to a loss of effective leadership and a potential decline in the quality and provision of public health services.

${ }^{*}$ Correspondence to: Alina L Flores, National Center on Birth Defects and Developmental Disabilities, Prevention Research and Translation Branch, Atlanta, USA, E-mail: ail5@cdc.gov

Key words: leadership, management

Received: May 15, 2018; Accepted: June 04, 2018; Published: June 07, 2018 


\section{Methods}

This paper focuses on the identification of factors that public health leaders consider as key aspects of a program to develop highly scientific public health staff into successful supervisors whose roles require mostly non-scientific management and leadership skills. In-depth interviews were conducted with 21 leaders at the Centers for Disease Control and Prevention (CDC) who had transitioned from scientific roles to broader leadership roles ${ }^{1}$.

\section{Results}

Interview participants identified 20 individual factors as key components of a public health leadership development program (Table 1). Factors described with greater frequency are described in further detail below.

Formal training was the most frequently mentioned factor that participants indicated as a key component of a leadership development program. Participants stated the need for on-the-job training early in one's career through mechanisms such as job shadowing or sharing. Participants also mentioned the need for a classroom component, and a phased approach by which the individual can gradually learn new skills.

"I think it would be something that could be at least a year or two, so that means you'd have to be thinking about people in the pipeline over a longer period of time. I think that there would be some didactic component to it. Not a lot but I think there has to be some."

The provision of opportunities for the respondent to do something new, step into a different role, or demonstrate a strength or skill was the second most frequently mentioned factor. Similar to the discussions related to formal training mentioned earlier, opportunities were often mentioned as occurring in a phased or stepwise manner. Mentions appeared related to the perceived need for an individual to show mastery of a skill beyond those typically associated with a scientific, public health role, such as personnel and budgetary management, and emotional awareness. Opportunities allow participants to decide if these alternate roles are a good fit and could be important especially in large technical organizations where individuals might not have the same exposure to duties beyond their specific disciplines until they are actually performing in their new role.

"Now they've got to worry about travel and budgets and personnel and all that stuff and they've never had to deal with this before. They have no experience and I think maybe there almost needs to be some kind of pathway or something where they can start learning about those things earlier on."

Another factor that interview participants indicated was a key component was having a mentor - both those who were experienced and trusted advisors for scientific issues as well as for leadership roles. While both formal mentoring through the CDC mentorship program and informal mentoring were discussed, interview participants most often talked about the importance of mentorship as part of a structured, formal process - either through a program offered by the organization or a more formalized agreement between mentor and mentee. This finding was notable given that only one interview participant had been in a formal mentoring relationship. Although all participants noted the positive impact informal mentors had on their own career

${ }^{1}$ Scientific roles were defined as discipline-specific and generally requiring subject matter expertise. Broader leadership roles were defined as managerial positions focused less on scientific content and more on administrative and supervisory functions. trajectories, most still discussed the need for formal mentorship as part of a leadership development program.

"I think one role would be mentoring. To find somebody who actually does it well and mentors well who could sort of model it for you. So maybe that's the idea of a detail or some other way you actually get to know somebody in that role before you took on the role."

Recognition of leadership potential was another factor mentioned; namely, identifying high potential employees and providing opportunities for them in a fair and equitable way.

"So maybe if there was a way to identify those people who would kind of excel and kind of bring them into the fold and use more energy towards developing people with some aptitude or desire - there might be one aspect of it." While the line of inquiry was related to key aspects of a program aimed at developing highly scientific public health staff into successful supervisory leaders, some interview participants indicated that a comprehensive program would ensure availability of advancement opportunities for staff who prefer to remain in scientific roles.

"Again, not every senior scientist needs to become a manager or supervisor and there needs to be a career progression that appreciates the contribution of the senior scientist in the absence of a management position."

Moreover, some participants noted that there are individuals who have a hard time leaving more scientific work once they enter into a role. This struggle can lead to frustration and a poor experience for both the individual and his/her employees. Interview participants mentioned both finding time to integrate scientific work into the new role, as well as staying in a scientific role for a longer period of time before transitioning out of it.

\section{Discussion}

This paper highlights a challenge in the field of public health around understanding the key components of a leadership development program to support the transition of scientific staff with expertise in public health content into non-scientific supervisory leadership roles. While this paper focuses specifically on public health scientists in a large federal public health agency, lessons learned may be applicable across the field of public health, such as in state and local public health departments and community-based public health organizations that might face similar challenges associated with providing leadership development for highly scientific public health staff.

Participants noted the need for hands-on, on-the-job learning. While extremely valuable, hands-on training can be difficult to execute in practice especially in large organizations where oversight, assistance and evaluation of individual performance might be challenging or in scientific organizations where employees might not seek experiences outside their disciplines. Further, with public health staff being asked to do more with less and balancing multiple responsibilities, it can be challenging for them to devote time to work outside of their roles. Hands-on training, however, can be integrated into existing classroom training efforts, with a more manageable number of individuals.

Having a phased approach to training also emerged. This approach could be especially positive for large, hierarchical organizations where the time it takes to enter into a leadership role can be lengthy and can help ensure that an individual has demonstrated skills proficiency before moving into leadership. Phased approaches also can be valuable in organizations with large numbers of entry-level staff. Organizations 
Table 1. Factors $(\mathrm{N}=20)$ Identified as Key Components of a Public Health Leadership Development Programs by Frequency of Mention

\begin{tabular}{|c|c|}
\hline Factor & Definition \\
\hline Training & $\begin{array}{l}\text { Attending or receiving formal training and instruction; includes both technical and non-technical, classroom and on-the-job training; excludes informal } \\
\text { training; longer term in duration, rather than a one-time, short-term course }\end{array}$ \\
\hline Opportunity & $\begin{array}{l}\text { A set of circumstances that makes it possible to advance, try something new, be promoted; deliberate action by an individual to open up a chance for } \\
\text { another; would be part of an innovative program for others seeking to transition; mentions are for individuals other than the actual respondent }\end{array}$ \\
\hline Stepwise Approach & Advancing within an organization or career in a staged manner rather than jumping quickly \\
\hline Mentor & $\begin{array}{l}\text { An experienced and trusted advisor; includes both formal mentoring through the } \mathrm{CDC} \text { mentorship program and informal mentoring; includes both scientific } \\
\text { and non-scientific mentors; importance of mentors for others or as part of discussion about what would be important as part of a development program }\end{array}$ \\
\hline Identifying High Potentials & Identification of staff with high potential to step into supervisory leadership roles; includes how to identify, when to identify, who would be identifying \\
\hline $\begin{array}{l}\text { Non-technical Track } \\
\text { (Supervisory Leadership } \\
\text { Track) }\end{array}$ & $\begin{array}{l}\text { Both as mentions of not needing to go into management or supervision and being able to stay in scientific role or mentions of a lack of advancement } \\
\text { opportunity for scientific staff }\end{array}$ \\
\hline Content of Program & Content of training programs to develop scientific staff into supervisory leadership staff \\
\hline Emotional Quotient & $\begin{array}{l}\text { Emotional quotient, a measure of a person's self-awareness, empathy, and ability to deal sensitively with other people; includes how you see yourself and } \\
\text { how others see you; other's perceptions of you; EQ that would be part of a development program for emerging leaders or mentions of EQ as important for } \\
\text { others }\end{array}$ \\
\hline $\begin{array}{l}\text { Staying Connected to } \\
\text { Science }\end{array}$ & $\begin{array}{l}\text { Mentions include encouraging staff to do science before entering into non science-only roles; also defined as mentions of how leaders can stay working in } \\
\text { the science realm }\end{array}$ \\
\hline New Responsibilities & Individual's responsibilities that emerge as part of a new role or presence as part of an activity \\
\hline Promotion & Discussion around how to move individuals within the agency, promotion potential \\
\hline Skills & $\begin{array}{l}\text { Having the skills, both scientific and supervisory leadership, to succeed in a leadership position; applies to mentions of what is needed once an individual is } \\
\text { already serving in a leadership capacity }\end{array}$ \\
\hline Exposure & Exposure that would be part of a development program for emerging leaders or mentions of exposure as important for others \\
\hline Communication & Written and oral communication skills with individuals at all levels as part of a leadership development program \\
\hline Hands on Learning & Importance of hands-on-learning for others or as part of discussion about what would be important as part of a development program \\
\hline Leadership Support & Leadership support that would be part of a development program for emerging leaders or mentions of leadership support as important for others \\
\hline Peers & Creating a peer group to support new leaders \\
\hline Infrastructure & Development of infrastructure that would be part of a development program for emerging leaders or mentions of infrastructure as important for others \\
\hline $\begin{array}{l}\text { Different from Technical } \\
\text { Role }\end{array}$ & Mentions of the need for aspiring leaders' understanding that leadership roles are different from the respondent's scientific work \\
\hline Role Model & Importance of role models for others or as part of discussion about what would be important as part of a development program \\
\hline
\end{tabular}

using a phased approach can begin developing their staff early in their careers, rather than providing rushed training when trying to fill vacancies.

The provision of opportunities emerged from the discussion, often as exposure to new roles and the chance to demonstrate skills. Providing opportunities for exposure could be relevant to organizations with employee roles that do not overlap or where employees are not exposed to other roles. Comprehensive leadership development programs can offer staff opportunities for exposure and learning outside the classroom that might influence their professional trajectories.

Mentorship was mentioned often throughout the interviews. It was notable that, while the participants indicated that formal mentoring was a key factor in a leadership development program, most had not taken part in a formal mentoring relationship. Integrating formal mentoring into a comprehensive leadership development program can help institutionalize mentorship, create accountability for application of training concepts, and expose staff to new roles and skills.

Discussions around identifying high potentials raised the issues of fairness and equity. There were concerns over what a high potential label would mean in terms of career growth and opportunities. By focusing on growing a talent pool rather than on identifying a single individual, organizations have a variety of potential candidates when openings become available. Two-way dialogue can provide supervisors with insight into both the needs of the organization and professional goals of their staff, and how to work with staff on developing skills that match these needs.
Finally, mentions of a scientific development path emerged during interviews. In some scientific organizations, top leadership positions often necessitate a supervisory component which can result in staff taking on supervisory roles they have not been developed for. A comprehensive leadership development program can include a development path for scientific staff who choose not to take on supervisory duties.

\section{Strengths and limitations}

There are several strengths to this study. First, no prior study conducted with CDC staff has examined what successful leaders identify as critical components of a leadership development program. Second, the use of a qualitative approach allowed for the emergence of a variety of responses based on the individual's own lived experience. There were also limitations. First, because participant selection was limited, other successful supervisors might not have been included in this study and their responses might have differed. Further, because only supervisory staff were interviewed, it is unclear whether nonsupervisory staff would have different perceptions of key factors for leadership development.

\section{Conclusion}

Organizations of all sectors and sizes are facing the retirement of senior level employees. These leaders are leaving organizations after long tenures and with vast institutional memory and skills. Other employees are stepping into vacant roles, often very quickly and without developing fully for their new responsibilities. In highly scientific organizations, an added concern is that scientists are filling 
non-science leadership vacancies often without having the skills or leadership competencies necessary to perform successfully in these roles. Moreover, the lack of a formalized leadership development program by which a broad talent pool can be created, and from which individuals with the necessary skills and competencies can be chosen, can widen the shortage of effective leaders.

The extent of current and future public health challenges requires a workforce prepared to address them [9]. By utilizing factors that have contributed to the success of existing leaders, public health organizations can take proactive steps toward growing and developing leaders from within their ranks and help ensure long-term sustainability and relevance of their organizations.

\section{Disclaimer}

The findings and conclusions in this report are those of the authors and do not necessarily represent the official position of the Centers for Disease Control and Prevention. The material is based upon a dissertation, submitted in partial fulfillment of the requirements for the doctoral degree at the School of Public Health of the University of Illinois at Chicago

\section{References}

1. Centers for Disease Control and Prevention (CDC). (2013) Modernizing the workforce for the public's health: shifting the balance-CDC Workforce Summit report. Atlanta, GA: US Department of Health and Human Services, CDC.

2. Maciag M (2013) The public employee 'silver tsunami' looms for governments. Retrieved from http://www.governing.com/topics/mgmt/gov-governments-silver-tsunami.html

3. Center for State and Local Government Excellence. (2014) State and local government workforce: 2014 Trends.

4. United States Government Accountability Office (U.S. GAO). (2014). Federal workforce: Recent trends in federal civilian employment and compensation. Retrieved from: http://www.gao.gov/products/GAO-14-215
5. Pourshaban D, Basurto-Davila R, Shih M (2015) Building and sustaining strong public health agencies: Determinants of workforce turnover. J Public Health Manag Pract 21: S80-S90. [Crossref]

6. Institute of Medicine (US) (1988) Committee for the study of the future of public health The future of public health. Washington, DC: National Academy Press. [Crossref]

7. Institute of Medicine (US) (2003) The future of the public's health in the $21^{\text {st }}$ century. Washington, DC: The National Academies Press. [Crossref]

8. Institute of Medicine (IOM) (2007) Training physicians for public health careers Washington, DC: National Academy Press.

9. DeSalvo K, Benjamin G (2016) Public health 3.0: A blueprint for the future of public health. Retrieved from http://healthaffairs.org/blog/2016/11/21/public-health-3-0-ablueprint-for-the-future-of-public-health/

10. Smith RR(2014) The growing (andretirementeligible) federal workforce. Retrieved from https://www.fedsmith.com/2014/01/30/the-growing-and-retirement-eligible-federalworkforce/

11. United States Department of Health and Human Services (USDHHS) (2016) Public health 3.0: A call to action to create a 21 st century public health infrastructure.

12. Cornerstone (2014) Creating the next generation of federal human capital: The 2014 state of human capital management report. Retrieved from https://www. cornerstoneondemand.com/sites/default/files/whitepaper/csod-wp-federal-humancapital-2014.pdf

13. Petrie N (2011) Future trends in leadership development (white paper). Greensborough, North Carolina: Center for Creative Leadership. 1-36.

14. de Beaumont Foundation. 2017. Building skills for a more strategic public health workforce: A call to action. Retrieved from http://www.debeaumont.org/wordpress/ wp-content/uploads/Building-Skills-for-a-More-Strategic-Public-Health-Workforce.pdf

15. Lang A, Thomas B (2013) Crossing the canyon: From technical expert to first-time leader Retrieved from http://www.ddiworld.com/DDI/media/articles/crossingthecanyon_ar_ td.pdf?ext=.pdf

16. McMichael AJ, Beaglehole R (2000) The changing global context of public health. The Lancet 356: 495-499. [Crossref]

17. Gebbie K, Merrill J, Tilson HH (2002) The public health workforce. Health Aff (Millwood) 21: 57-67. [Crossref]

18. Hunter EL (2015) Rebooting our boots on the ground. Journal of Public Health Management and Practice 21: S1-S2.

Copyright: (C2018 Flores AL. This is an open-access article distributed under the terms of the Creative Commons Attribution License, which permits unrestricted use, distribution, and reproduction in any medium, provided the original author and source are credited. 